\title{
Ibuprofen Suppresses Plaque Pathology and Inflammation in a Mouse Model for Alzheimer's Disease
}

\author{
G. P. Lim, ${ }^{1,3}$ F. Yang, ${ }^{1,3}$ T. Chu, ${ }^{1,3}$ P. Chen, ${ }^{1,3}$ W. Beech, ${ }^{1,3}$ B. Teter, ${ }^{1,3}$ T. Tran, ${ }^{1,3}$ O. Ubeda, ${ }^{1,3}$ K. Hsiao Ashe, ${ }^{5}$ \\ S. A. Frautschy, ${ }^{1,2,3,4}$ and G. M. Cole . $^{1,2,3,4}$ \\ University of California Los Angeles, Departments of ${ }^{1}$ Medicine and 2 Neurology, Los Angeles, California 90095, ${ }^{3}$ The \\ Greater Los Angeles Veterans Affairs Healthcare System, and ${ }^{2}$ Veterans Administration Medical Center Geriatric Research, \\ Education, and Clinic Center, Sepulveda, California 91343, and 5Center for Clinical and Molecular Neurobiology, \\ Departments of Neurology and Neuroscience, University of Minnesota, Minneapolis, Minnesota 55455
}

\begin{abstract}
The brain in Alzheimer's disease (AD) shows a chronic inflammatory response characterized by activated glial cells and increased expression of cytokines and complement factors surrounding amyloid deposits. Several epidemiological studies have demonstrated a reduced risk for $A D$ in patients using nonsteroidal anti-inflammatory drugs (NSAIDs), prompting further inquiries about how NSAIDs might influence the development of AD pathology and inflammation in the CNS. We tested the impact of chronic orally administered ibuprofen, the most commonly used NSAID, in a transgenic model of AD displaying widespread microglial activation, age-related amyloid deposits, and dystrophic neurites. These mice were created by overexpressing a variant of the amyloid precursor protein found in familial AD. Transgenepositive $(\mathrm{Tg}+)$ and negative $(\mathrm{Tg}-)$ mice began receiving chow containing 375 ppm ibuprofen at 10 months of age, when amyloid plaques first appear, and were fed continuously for 6 months. This
\end{abstract}

A chronic inflammatory response characterized by activated microglia, reactive astrocytes, complement factors, and increased inflammatory cytokine expression associated with $\beta$-amyloid deposits has been described in the brains of Alzheimer's patients (Rogers et al., 1996). Evidence that this inflammation contributes to the pathogenesis of Alzheimer's disease (AD) has stemmed from 20 retrospective epidemiological studies and one prospective, longitudinal study showing up to a $50 \%$ reduction in the risk of AD associated with nonsteroidal anti-inflammatory drug (NSAID) consumption (Stewart et al., 1997; McGeer and McGeer, 1998). Ibuprofen was the most frequently used anti-inflammatory drug in these studies, taken by $39-50 \%$ of the subjects (Breitner et al., 1995; Stewart et al., 1997). These studies raise the question of how NSAIDs, particularly the nonprescription medication ibuprofen, might influence CNS inflammation and AD pathology.

To address this problem, we used a previously described transgenic mouse, $\operatorname{Tg}(\mathrm{HuAPP} 695 . \mathrm{K} 670 \mathrm{~N}-\mathrm{M} 671 \mathrm{~L}) 2576$ (Tg2576), with amyloid pathology and activated microglia (Hsiao et al., 1996; Frautschy et al., 1998). These mice, which overexpress the 695 amino acid form of human amyloid precursor protein (APP) containing a double mutation found in a Swedish kindred with familial $\mathrm{AD}$, display age-related hippocampal and neocortical amyloid de-

Received April 1, 2000; accepted May 5, 2000.

This work was supported by National Institute on Aging Grants AG13471 (G.M.C.) and AG15453 (K.H.A.), Veterans Affairs Merit, the Alzheimer Association, the Elizabeth and Thomas Plott Family Foundation, and the Katherine and Benjamin Kagan Alzheimer's Treatment Program. We thank Boris Oks, Robert McBean, and Ulises Garcia for their excellent work genotyping the transgenic mice. We also thank Mychica Simmons for assistance with the amyloid and ubiquitin image analysis. We are grateful to Dr. Judith Harker for her help with the statistical analyses.

Correspondence should be addressed to Dr. Greg M. Cole, Sepulveda VAMC GRECC 11E, University of California Los Angeles, Department of Medicine and Neurology (SFVP), 16111 Plummer Street, Sepulveda, CA 91343. E-mail: gmcole@ucla.edu.

Copyright (C) 2000 Society for Neuroscience $0270-6474 / 00 / 205709-06 \$ 15.00 / 0$ treatment produced significant reductions in final interleukin- $1 \beta$ and glial fibrillary acidic protein levels, as well as a significant diminution in the ultimate number and total area of $\beta$-amyloid deposits. Reductions in amyloid deposition were supported by ELISA measurements showing significantly decreased SDS-insoluble $A \beta$. Ibuprofen also decreased the numbers of ubiquitin-labeled dystrophic neurites and the percentage area per plaque of antiphosphotyrosine-labeled microglia. Thus, the anti-inflammatory drug ibuprofen, which has been associated with reduced AD risk in human epidemiological studies, can significantly delay some forms of $A D$ pathology, including amyloid deposition, when administered early in the disease course of a transgenic mouse model of AD.

Key words: inflammation; cytokines; microglia; amyloid; Alzheimer; NSAID posits first appearing at $\sim 10$ months of age, as well as microglial activation, reactive astrocytes with increased glial fibrillary acidic protein (GFAP), and dystrophic neurites. Plaque-associated reactive microglia in these mice also show enhanced staining for tumor necrosis factor- $\alpha$ (TNF- $\alpha$ ) and interleukin- $1 \beta$ (IL-1 $\beta$ ) (Benzing et al., 2000), two pro-inflammatory cytokines elevated in microglia of brains from AD patients (Dickson et al., 1993; Griffin et al., 1998). To determine whether the development of AD-related pathology is sensitive to ibuprofen treatment, we analyzed brain tissue of ibuprofen-fed Tg2576 mice for changes in levels of IL-1 $\beta$, GFAP, activated microglia, dystrophic neurites, amyloid plaques, and detergent-insoluble and water-soluble amyloid $\beta$-protein $(\mathrm{A} \beta)$. Ten-month-old Tg2576 mice were fed chow containing no drug or ibuprofen $(375 \mathrm{ppm})$ for 6 months. We found that a chronic dose of oral ibuprofen reduced changes in levels of all these parameters, indicating that ibuprofen can significantly interfere with the development of some forms of AD pathology in this transgenic mouse model of AD.

\section{MATERIALS AND METHODS}

Animals. Ten-month-old male and female $\mathrm{Tg} 2576 \mathrm{Tg}+$ and $\mathrm{Tg}-$ mice from 12 litters were randomly split between treatment groups. Tg + mice were fed either chow (Research Diets, New Brunswick, NJ) containing ibuprofen (Sigma, St. Louis, MO; $375 \mathrm{ppm} ; n=9)$ or no drug $(n=8)$ for 6 months before being sacrificed. Tg littermates were fed the same chow containing no drug $(n=5)$ or ibuprofen $(n=9)$. One animal was removed from the study for failure to gain weight. At the time of sacrifice, neither the weights nor the ages of the mice were significantly different. Animals were perfused before brain dissection with $0.9 \%$ normal saline followed by HEPES buffer, $\mathrm{pH}$ 7.2, containing protease inhibitors. Brain regions were dissected from one hemisphere using mouse brain atlas coordinates (Franklin and Paxinos, 1997). One brain hemisphere was lined up with the interaural line at $0 \mathrm{~mm}$. From the interaural line, vertical cuts were made at +3 and $+0.72 \mathrm{~mm}$, just posterior to the mammillary bodies. Thalamic, cortical, and hippocampal regions, as well as entorhinal cortex and piriform cortex/amygdala sections, were dissected out and snap-frozen in liquid nitrogen. Biochemical measurements were performed in the hippocampus, 
entorhinal cortex, piriform cortex/amygdala, and residual cortex (cortex region without frontal, entorhinal, or piriform areas). The other brain hemisphere was fixed in 4\% paraformaldehyde, processed in 10-20\% sucrose, frozen in liquid nitrogen, and sectioned $(10 \mu \mathrm{m})$ for immunohistochemistry.

Tissue preparation. Tissue samples were homogenized in 10 wet weight volumes of TBS, $\mathrm{pH} 8.0$, containing a cocktail of protease inhibitors $(20$ $\mu \mathrm{g} / \mathrm{ml}$ each of pepstatin $\mathrm{A}$, aprotinin, phosphoramidon, and leupeptin, 0.5 $\mathrm{mM}$ PMSF, and $1 \mathrm{~mm}$ EGTA). Samples were sonicated briefly $(10 \mathrm{~W}, 2 \times$ $5 \mathrm{sec}$ ) and centrifuged at $100,000 \times g$ for $20 \mathrm{~min}$ at $4^{\circ} \mathrm{C}$. The soluble fraction (supernatant) was used for IL-1 $\beta$ or $\mathrm{A} \beta$ ELISAs. To analyze insoluble $\mathrm{A} \beta$, the SDS-insoluble pellet was solubilized and sonicated in $70 \%$ formic acid. The extract was neutralized with $0.25 \mathrm{M}$ Tris, $\mathrm{pH} 8.0$, containing $30 \%$ acetonitrile and $5 \mathrm{M} \mathrm{NaOH}$ before loading onto the ELISA plate.

Sandwich ELISA for A $\beta$. Monoclonal 4G8 against A $\beta 17-24$ (Senentek, Napa, CA) was used as the capture antibody at $3 \mu \mathrm{g} / \mathrm{ml}$ in $0.1 \mathrm{M}$ carbonate buffer, pH 9.6, in a Dynex 96 well plate. Blocking was completed with $2 \%$ bovine serum albumin in TBS. Processed and neutralized samples were diluted with EC buffer (TBS containing $0.1 \mathrm{mM}$ EDTA, $1 \%$ BSA, and $0.05 \%$ 3-[(3-cholamidopropyl)dimethylammonio]-1-propanesulfonic acid (CHAPS), $\mathrm{pH} 7.4$, containing protease inhibitors $(20 \mu \mathrm{g} / \mathrm{ml}$ each of pepstatin, aprotinin, phosphoramidon, and leupeptin, $0.5 \mathrm{~mm}$ PMSF, $1 \mathrm{~mm}$ EGTA, and 2 mM EDTA). Equal volumes of sample and detector antibody (biotinylated 10G4, against amino acids 5-13; 1:500) were loaded onto the wells overnight at $4^{\circ} \mathrm{C}$. The reporter system was streptavidin-alkaline phosphatase using AttoPhos (JBL Scientific, San Luis Obispo, CA) as the substrate. Fluorescence of the product was monitored at an excitation wavelength of $450 \mathrm{~nm}$ and an emission wavelength of $580 \mathrm{~nm}$.

Sandwich ELISA for IL-1 $\beta$. A polyclonal antibody against mouse IL-1 $\beta$ (Endogen, Woburn, MA) was used as the capture antibody at $2 \mu \mathrm{g} / \mathrm{ml}$ in PBS in a Dynex 96 well plate. Blocking was completed with $2 \%$ bovine serum albumin in TBS. Equal amounts of sample $(80 \mu \mathrm{g}$ of brain protein extract) were loaded onto the wells overnight at $4^{\circ} \mathrm{C}$. A monoclonal antibody against mouse IL1- $\beta$ (Endogen; $0.5 \mu \mathrm{g} / \mathrm{ml}$ ) was used as the detecting antibody. The development of the ELISA was performed as described above for $A \beta$. The minimum detectable quantity of IL- $\beta$ was 0.5 pg under most conditions.

Immunoblot of GFAP. Brain homogenates $(50 \mu \mathrm{g})$ were electrophoresed on a $10 \%$ acrylamide gel under reducing conditions. Proteins were transferred to a polyvinylidene difluoride membrane (400 mA for $2 \mathrm{hr}$ ) before blocking in $10 \%$ nonfat dry milk and $0.1 \%$ gelatin in PBS for $1.5 \mathrm{hr}$. Blots were incubated with monoclonal antibodies against GFAP (Sigma) overnight at $4^{\circ} \mathrm{C}$. After three rinses, blots were incubated in HRP-conjugated goat anti-mouse $(1: 10,000)$ for 45 min before development with SuperSignal (Pierce, Rockford, IL). Bands were analyzed using densitometric software (Molecular Analyst II).

Immunostaining and image analysis. Ten micrometer hemibrain cryostat sections were cut from the posterior pole to the anterior margin of the hippocampus. Anti-phosphotyrosine (anti-PT) staining was performed on cryostat sections from middle hippocampus as previously described (Frautschy et al., 1998). To identify neuritic plaques, sections were incubated overnight at $4^{\circ} \mathrm{C}(1: 100)$ in "DAE" polyclonal antibody (anti-A $\beta 1-13$ ) made against synthetic peptides $A \beta 1-13$ and named after the first three amino acids of the $\mathrm{A} \beta$ peptide, Asp-Ala-Glu. Vascular amyloid was labeled overnight at $4^{\circ} \mathrm{C}$ with a polyclonal antibody anti-A $\beta 34-40$ (Mak et al. 1994). Dystrophic neurites were labeled overnight at $4^{\circ} \mathrm{C}$ with a polyclonal antibody against ubiquitin (1:500; Dako, Carpinteria, CA). Slides were incubated in biotinylated goat anti-rabbit antibodies $(1: 1000)$ followed by $\mathrm{ABC}$ reagent, each for $30 \mathrm{~min}$ at $37^{\circ} \mathrm{C}$. Sections were developed using peroxidase/DAB (Pierce). If sections were double-labeled for DAE, immunostaining was developed with alkaline phosphatase substrate kit III (Vector Laboratories, Burlingame, CA)

For image analysis of DAE and ubiquitin staining, we examined immunolabeling from three coronal sections taken from anterior (bregma, -1.22 $\mathrm{mm}$ ), middle (bregma, $-1.70 \mathrm{~mm}$ ), and posterior hippocampus (bregma, $-2.80 \mathrm{~mm}$ ) of $\mathrm{Tg}+$ animals treated or untreated with ibuprofen. Specifically, residual cortex areas were defined as the cortical region dorsal to the rhinal fissure, whereas entorhinal and piriform/amygdala regions were defined as areas ventral to the rhinal fissure on coronal sections. All images were acquired from an Olympus Vanox-T (AHBT) microscope with an Optronix Engineering LX-450A CCD video system. The video signal was routed into a Macintosh computer via a Scion Corporation AG-5 averaging frame grabber, and these digitized images were analyzed with NIH Image public domain software. Custom Pascal macro subroutines were written to calculate various parameters of DAE and ubiquitin immunostaining. DAE parameters included number of plaques, mean diameter, mean area, mean percentage area, and total area of plaques. Ubiquitin parameters consisted of the number of small particles (ranging from 3 to $25 \mu \mathrm{m}$ ), mean area and total area of small ubiquitin particles, and percentage area of positively stained particles per subregion. Analysis of anti-PT immunostaining was performed using a quantitative ring analysis as previously described (Frautschy et al., 1998).

Statistical analyses. A two-factor ANOVA (diet $\times$ region or transgene $\times$ region) was performed to analyze differences in IL-1 $\beta$ and GFAP levels, $\mathrm{A} \beta$ levels, and image analysis data. Post hoc comparisons between regions were performed using Fisher's protected least significant difference. Bar- tlett's test for homogeneity of variances was also performed to determine whether variances were equal. Some analyses required logarithmic or square root transformations to establish homogeneity. $P$ values $<0.05$ were considered significant.

\section{RESULTS}

\section{Ibuprofen decreases IL-1 $\beta$ and GFAP levels in brains of transgenic animals}

IL-1 $\beta$ levels were quantified in brain supernatant extracted from dissected brain regions in three groups of mice: $\mathrm{Tg}+$ mice fed control diet, $\mathrm{Tg}-$ mice fed control diet, and $\mathrm{Tg}+$ mice fed ibuprofen diet. Dissected brain regions included hippocampus, entorhinal cortex, piriform cortex/amygdala, and residual cortex. Results analyzed by ANOVA revealed a significant transgene-dependent increase in IL-1 $\beta$ in hippocampal and residual cortical regions $\left(F_{(1,21)}\right.$ $=19.934 ; p=0.0002$ ) (Fig. $1 A$ ), but not in entorhinal and piriform/ amygdala areas $\left(F_{(1,20)}=2.696 ; p=0.11\right)$. Hippocampus and residual cortex data were grouped together because their variances were more similar to each other than entorhinal and piriform cortex regions. Levels of IL- $1 \beta$ were elevated 2.4 -fold in hippocampus and 6.7-fold in residual cortex. ANOVA analyses showed an overall treatment effect in all regions $\left(F_{(1,50)}=13.689 ; p=0.0005\right)$ (Fig. $1 B$ ). There was also a significant treatment-region interaction, indicating that reductions in $\mathrm{IL}-1 \beta$ levels were dependent on region. Levels were decreased $75 \%$ in hippocampus and $68 \%$ in residual cortex.

Western analysis was used to determine the effect of ibuprofen treatment on GFAP levels in Tg2576 mice. GFAP is a marker of astrocytosis that is elevated with age in mammals and is increased in amyloid-forming APP transgenic mice (Laping et al., 1994; Irizarry et al., 1997). ANOVA analyses demonstrated an overall transgene-dependent increase in GFAP levels $\left(F_{(1,38)}=37.997\right.$; $p=0.001$ ) (Fig. $1 C$ ), that was region-dependent $\left(F_{(3,38)}=7.693\right.$; $p=0.004)$. GFAP levels were significantly lower in the ibuprofentreated group $\left(F_{(1,48)}=4.891 ; p=0.03\right)$, with no significant treatment-region interaction (Fig. 1D). Regionally, the largest transgene-associated increase in GFAP was observed in entorhinal cortex (7.1-fold), whereas GFAP levels were reduced $76 \%$ with ibuprofen treatment. Smaller (1.25- to 2-fold) transgene-dependent elevations in GFAP were observed in other regions, whereas relatively lesser $15-25 \%$ reductions were observed with ibuprofen treatment.

\section{Microglial activation is significantly decreased in ibuprofen-treated mice}

Quantitative morphometric image analysis of anti-PT-labeled microglia was previously used to demonstrate evidence of activated microglia clustered within and around plaques in aging $\mathrm{Tg} 2576$ mice (Frautschy et al., 1998). This ring analysis, which quantifies PT-labeled microglia within four plaque-centered rings one to four plaque radii from the center of $A \beta$-labeled deposits, was performed on cryostat sections stained for $\mathrm{A} \beta$ (DAE, blue) and microglia (PT, brown). Results of double-blind ring analysis of plaques in parietal and temporal cortex and hippocampus showed that the percentage of area occupied by PT-labeled microglia was significantly decreased in the ibuprofen group (Fig. $2 A$ ). Within four plaque radii from plaque center, there was a $29 \%$ reduction $\left(F_{(1,1472)}=56.208\right.$; $p<0.0001)$ in the area covered by activated microglia in the ibuprofen group. Two-factor ANOVA analysis showed a significant treatment-ring interaction, indicating that the ibuprofenassociated reductions of microglial activation were dependent on distance from the $\mathrm{A} \beta$ deposits. Microglial activation decreased significantly within and immediately adjacent to $\mathrm{A} \beta$-labeled plaques (rings 1 and 2; $p<0.0001$ ), but not significantly in outlying rings 3 and 4 (Fig. 2B).

The effect of ibuprofen on microglial staining was more dramatic outside the plaques (ring 2) than within the plaques (ring 1). This effect is illustrated in Figure 3, in which sections of piriform cortex/amygdala regions from $\mathrm{Tg}+$ mice fed control diet $(D)$ and $\mathrm{Tg}+$ fed ibuprofen $(E)$ were double-labeled for $\mathrm{A} \beta$ (Vector, blue) 


\section{$\mathrm{IL}-1 \beta$}
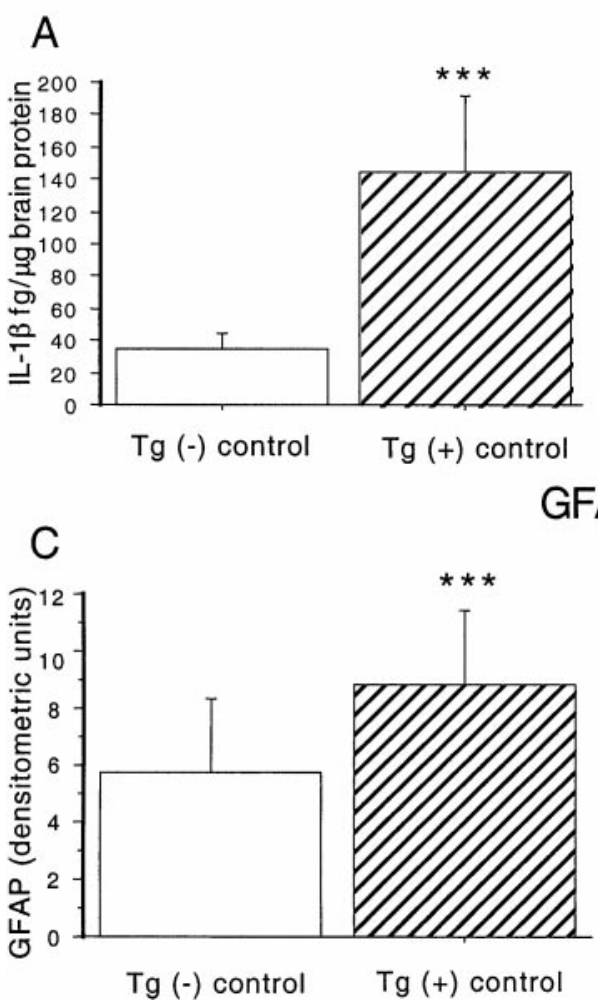

B

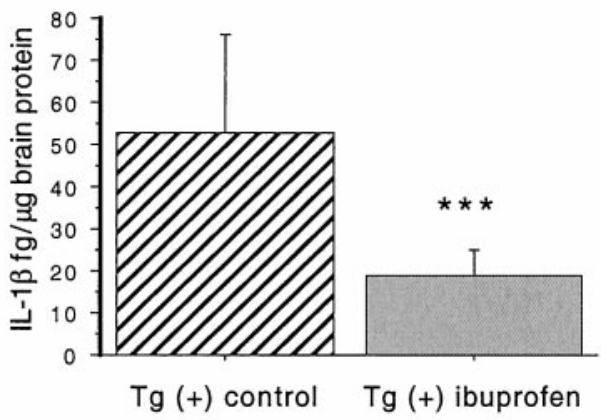

Figure 1. Effect of ibuprofen on IL-1 $\beta$ levels and GFAP levels in Tg2576 brains. $A, B$, IL- $1 \beta$ measurements. ANOVA analyses were performed on measurements in $\mathrm{Tg}-$ mice fed control diet $(n=5), \mathrm{Tg}+$ mice fed control diet $(n=$ $8)$, and $\mathrm{Tg}+$ mice fed ibuprofen $(n=9) . A$, Measurement of IL-1 $\beta$ levels in hippocampus and residual cortex in 16-month-old $\mathrm{Tg}+$ and $\mathrm{Tg}-$ mice. IL- $1 \beta$ protein levels were measured in TBS-extracted supernatant fractions from $\mathrm{Tg}-$ mice fed control diet (open bar) and $\mathrm{Tg}+$ mice fed control diet (hatched bar). Levels were significantly increased in both regions in $\mathrm{Tg}+$ compared to Tg- animals. $B$, Effect of ibuprofen on IL- $1 \beta$ levels in $\mathrm{Tg}+$ mice. IL- $1 \beta$ was decreased by $64.7 \%$ across all regions in ibuprofen-treated animals. Equality of variance was established with a logarithmic transformation. $C, D$, GFAP levels. $C$, Effect of transgene on GFAP levels. Semiquantitative measurements of GFAP were performed on immunoblots of $\mathrm{Tg}-$ and $\mathrm{Tg}+$ animals fed control diet. A highly significant $51.7 \%$ elevation in $\mathrm{Tg}+$ animals was found. $D$, Effect of ibuprofen on GFAP levels in $\mathrm{Tg}+$ mice. Treatment with ibuprofen significantly decreased GFAP levels $20 \%$ across all regions in Tg + animals. ${ }^{*} p<0.05$. $*_{* *}^{*} p<0.001$. Error bars indicate SE.
A

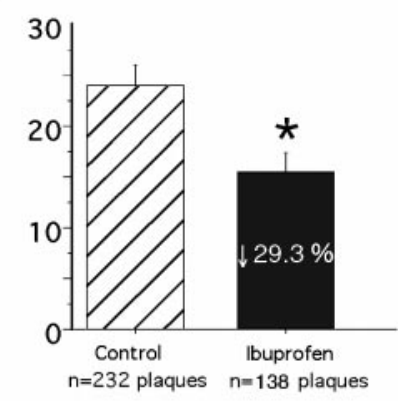

B

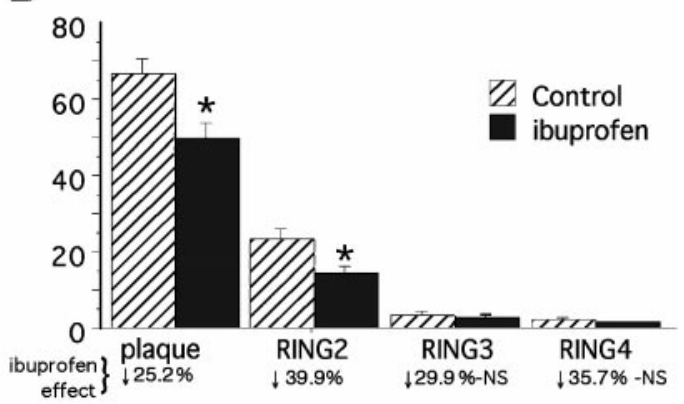

Figure 2. Image analysis of phosphotyrosine-labeled microglia. Histograms illustrate the percentage of antiPT-stained microglial area plus or minus $95 \%$ confidence interval in and around $\mathrm{A} \beta$-stained plaque deposits in $\mathrm{Tg}+$ mice on either a control diet $(n=6$ mice $)$ or ibuprofen diet ( $n=5$ mice $)$ in the midhippocampal region (bregma, $-1.70 \mathrm{~mm}$ ). An average of $37 \pm 6.0$ and $27.35 \pm 7.6$ plaques were counted per mouse in the control and ibuprofen diets, respectively. $A$ illustrates that ibuprofen induced a $29.3 \%$ reduction in the percentage of PT-stained area within four plaque radii from $\mathrm{A} \beta$-stained plaque center, compared to the control diet $(p<0.0001)$. Logarithmic transformation was needed to establish homogeneity of variance. $B$, Two-way ANOVA (treatment $\times$ ring) showed significant treatment and ring effects as well as a significant treatmentring interaction $\left({ }^{*} p<0.0001\right)$. This histogram shows the greater reduction in PT-stained microglia in radii outside the plaque compared to within the plaque (each ring corresponds to one plaque radii). NS, Not statistically significant.

and phosphotyrosine (diaminobenzidine, brown). In brains of $\mathrm{Tg}+$ mice fed control diet in which PT labeling was upregulated, A $\beta$ deposits (purple) are surrounded by activated microglia (brown), which are more numerous when close to (arrowheads) than when distal to deposits (arrows). Compared to microglia surrounding plaques in $\mathrm{Tg}+$ mice fed control diet $(F)$, fewer microglia cluster around plaques in the $\mathrm{Tg}+$ mice fed ibuprofen $(E)$.

\section{Amyloid pathology is reduced by ibuprofen}

To evaluate the effect of ibuprofen on amyloid and plaque pathology, cryostat sections from anterior to posterior hippocampus were immunostained for $\mathrm{A} \beta$ using a rabbit polyclonal antibody made to synthetic $\mathrm{A} \beta 1-13$ peptide ("DAE"). This antibody labeled plaques similarly to the commercially available mouse monoclonal antibody, 4G8 (Senentek) (data not shown), and more robustly than anti-A $\beta 34-40$ (Fig. 3A), but exhibited lower levels of endogenous $\mathrm{IgG}$ artifacts associated with using mouse antibodies on mouse tissue. An example of anti-A $\beta$ DAE immunostaining of piriform cortex/amygdala of $\mathrm{Tg}+$ mice fed control diet is shown in Figure $3 B$. Using NIH Image public domain software, sections were analyzed for total plaque counts, plaque size, and total area of plaques.
The ibuprofen diet group had significantly fewer (53\%) overall plaque numbers compared to the control diet group analyzed across all regions $\left(F_{(1,28)}=5.78 ; p=0.02\right)$ (Table 1$)$. The treatment group also showed a reduction in the overall percentage and total area staining for $\mathrm{A} \beta$ by $53 \%\left(F_{(1,28)}=3.603 ; p=0.07\right)$ and $56 \%$ $\left(F_{(1,28)}=5.515 ; p=0.01\right)$, respectively, compared with the control diet group. A $57 \%$ reduction in percentage area stained was observed in residual cortex of ibuprofen-treated animals. Ibuprofen treatment did not affect plaque size (mean area) $\left(F_{(1,28)}=0.032\right.$; $p=0.85)$. None of the treatment effects on amyloid deposits showed a significant dependence on region.

In addition to analysis of $\mathrm{A} \beta$ immunohistochemically, the effect of ibuprofen on $\mathrm{A} \beta$ levels in the opposite hemisphere was also analyzed biochemically in dissected brain regions by an ELISA that detects total $\mathrm{A} \beta$. "Soluble" $\mathrm{A} \beta$ was first extracted with TBS and then in $2 \%$ SDS, and the remaining SDS "insoluble" A $\beta$ was pelleted at $100,000 \times g$ and extracted with $70 \%$ formic acid. Insoluble $\mathrm{A} \beta$ levels were significantly decreased overall by $39 \%$ in the ibuprofen-treated mice $\left(F_{(1,50)}=4.709 ; p=0.03\right)$ (Fig. $4 A$ ). There was no significant treatment-region interaction, indicating 


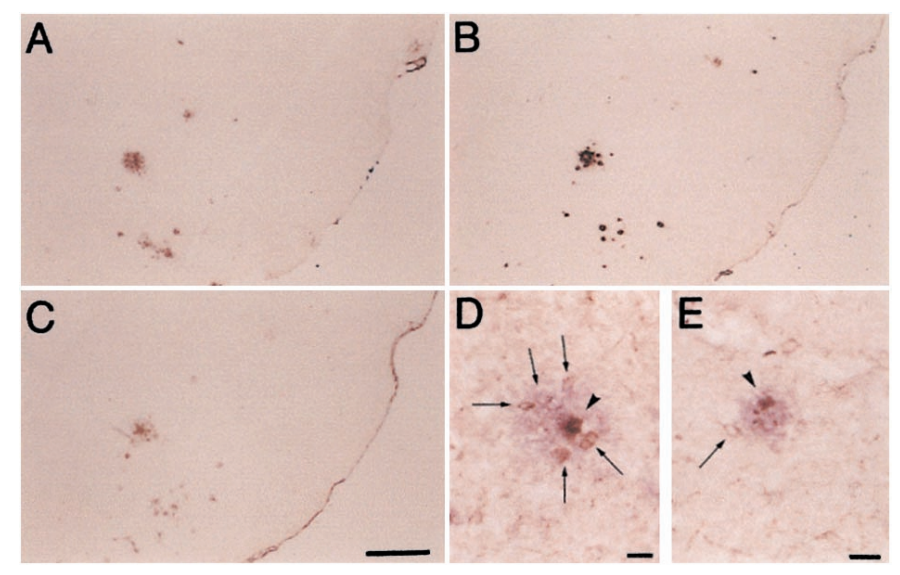

Figure 3. Representative examples of immunostaining of piriform cortex/ amygdala regions from $\mathrm{Tg}+$ mice fed control diet. $A$ and $B$ show staining with anti-A $\beta 34-40(A)$ and DAE $(B)$. Magnification for both is $25 \times$. These antibodies are rabbit polyclonal antisera made to synthetic peptides representing $\mathrm{A} \beta$ 34-40 (Mak et al. 1994) and $\mathrm{A} \beta$ 1-13, respectively. $C$ shows staining with a rabbit polyclonal antibody made to ubiquitin conjugates (Dako; magnification $25 \times)$. $\mathrm{Tg}+$ mice fed control diet $(D$, magnification $100 \times)$ and $\mathrm{Tg}+$ mice fed ibuprofen diet $(E$, magnification $132 \times)$ show double labeling with a monoclonal anti-phosphotyrosine (brown) followed by a light development of DAE (blue). Arrowheads depict microglia (within A $\beta$-labeled plaque), whereas arrows show microglia surrounding the plaque.

that the reduction of insoluble $\mathrm{A} \beta$ was fairly uniform across regions. Analysis of individual regions showed the greatest reduction of $40 \%$ in the residual cortex $(54.7 \mathrm{ng}$ of control diet vs $32.7 \mathrm{ng}$ of ibuprofen diet), with a consistent trend for reductions of $20-35 \%$ in every other region. Two-factor ANOVA for soluble A $\beta$ similarly demonstrated that levels were decreased overall by $34 \%$ in the ibuprofen-treated group (Fig. $4 B)\left(F_{(1,41)}=3.683 ; p=0.06\right)$, with no significant treatment-region interaction. Regionally, strong trends toward ibuprofen-associated reductions in soluble $\mathrm{A} \beta$ were found in all regions varying from 21 to $62 \%$.

\section{Ubiquitin-positive structures are significantly decreased in number with ibuprofen}

The effect of ibuprofen on the numbers and size of small ubiquitinpositive profiles (neurites) was measured using image analysis of cryostat sections immunolabeled with anti-ubiquitin from mice fed either ibuprofen or control diet. A representative example of this labeling is seen in Figure $3 C$. Anti-ubiquitin labeled no neurites in $\mathrm{Tg}$ - mice. Double labeling in $\mathrm{Tg}+$ mice with anti-A $\beta$ or synaptic markers revealed most ubiquitin staining in plaque-associated dystrophic neurites (data not shown). Image analysis (NIH Image) revealed that the numbers of small ubiquitin-labeled dystrophic neurites (ranging from 3 to $20 \mu \mathrm{m}$ in diameter) were decreased by $48 \%$ in the ibuprofen group $\left(F_{(1,30)}=4.903 ; p=0.03\right.$ ) (Table 2 ). Whereas the average size of small particles was increased by $31 \%$, the mean percentage of area occupied by ubiquitin-positive small particles was significantly smaller with ibuprofen $(67 \%)$ than in the control group $\left(F_{(1,30)}=9.299 ; p=0.005\right)$. Furthermore, the total area of ubiquitin-positive staining was decreased by $51 \%$ in ibuprofen-treated animals $\left(F_{(1,30)}=7.058 ; p=0.01\right)$, indicating that ibuprofen affected dystrophic neurite pathology. None of these treatment effects were region-dependent.

\section{DISCUSSION}

In this study we found that ibuprofen, a commonly used nonprescription NSAID associated with reduced AD risk in epidemiological studies, decreased inflammation, dystrophic neurite formation, and amyloid deposition in aging transgenic mice expressing a familial AD gene. This is the first report to demonstrate significant effects of NSAID treatment on AD pathology in a transgenic Alzheimer's model.
The mechanism by which NSAIDs reduce the risk of Alzheimer's disease is unknown. Two possibilities are: (1) NSAIDs decrease the inflammatory reaction engendered by amyloid deposits, leading to diminished neurotoxicity; and (2) NSAIDs attenuate the production of inflammatory cytokines, such as IL- $1 \beta$ and transforming growth factor- $\beta$ (TGF- $\beta$ ), and products of reactive glia, such as apolipoprotein $\mathrm{E}(\mathrm{ApoE})$, which have been implicated in amyloid deposition (Mrak et al., 1995; Wyss-Coray et al., 1997; Harris-White et al., 1998). The results of our study strongly support the latter hypothesis, because amyloid deposition was dramatically suppressed with ibuprofen treatment. Support for the former hypothesis was less obvious and more difficult to assess, because traditional measures of neurotoxicity such as neuron loss and a reduction in synaptic markers are not evident in 16-month-old $\mathrm{Tg}$ 2576 mice (Irizarry et al., 1997). However, the percentage of plaque area occupied by microglia was smaller in treated animals, suggesting a decreased inflammatory reaction per plaque. One measure of neurotoxicity, the area occupied by ubiquitin-labeled dystrophic neurites, was diminished $48 \%$ in ibuprofen-treated mice, but this reduction in dystrophic neurites could be directly related to the reduction in amyloid deposition because final plaque number and total plaque area decreased 52-56\% with ibuprofen treatment.

Ibuprofen also reduced both water-soluble and SDS-insoluble $\mathrm{A} \beta$ by 34 and $40 \%$, respectively, effects that were less pronounced that the $>50 \%$ decrease in amyloid plaque deposition. The inclusion of vascular $\mathrm{A} \beta$ in the ELISA, but not in the image analyses of amyloid deposits, may have limited the size of the ibuprofen effect in the biochemical measurements of $\mathrm{A} \beta$ relative to the immunohistochemical measurements. Because $\mathrm{A} \beta 40$ comprises $>50 \%$ of the total $\mathrm{A} \beta$ in $\mathrm{Tg} 2576$ mice (Hsiao et al., 1996) and is the major component of vascular amyloid, we stained vascular amyloid with anti-A $\beta 34-40$ in $\mathrm{Tg}+$ mice and found ibuprofen had no significant effect on the amount of vascular $A \beta 40$ immunoreactivity in meningeal and plexus vessels (data not shown).

The observed reduction in soluble $A \beta$ by ibuprofen treatment at an early stage might contribute to a decrease in amyloid seeds and subsequent plaque numbers. This could occur through its influence on microglia, which have been proposed to affect the formation or clearance of small, diffusible A $\beta$ oligomers or multimers (Ard et al., 1996), or through an effect on ApoE, TGF $\beta$ s, or other cytokine circuits with diffusible effectors (Griffin et al., 1998). In AD brain, soluble $\mathrm{A} \beta$ is sixfold higher than in control brains and contains both monomers and oligomers (10 to $>100 \mathrm{kDa})$, hypothesized to be seeds or precursors to insoluble, filamentous amyloid (Kuo et al., 1996). Soluble A $\beta$ levels in residual cortex of 16-month-old untreated Tg2576 mice averaged $174.6 \mathrm{pmol} / \mathrm{gm}$ tissue but were less than $60 \mathrm{pmol} / \mathrm{gm}$ tissue in 3- to 4-month-old Tg2576 mice (data not shown). The attenuation of this rise by ibuprofen in Tg2576 mice supports the possibility that small $\mathrm{A} \beta$ aggregates or oligomers were reduced by this treatment. In humans a greater impact of NSAID treatment at an earlier stage of AD has been suggested by two epidemiological studies, which found a greater risk reduction when NSAID use was begun more than 2 years before diagnosis (Stewart et al., 1997; In't Veld et al., 1998). Conversely, the lack of effect of NSAIDs on plaque numbers in the mesial temporal cortex of clinically normal elderly control and arthritic patients (Mackenzie and Munoz, 1998) might be explained by the fact that plaques stop accumulating rapidly with age in this brain area (Mackenzie et al., 1995), obscuring any potential effect on plaque initiation that NSAID consumption could produce.

Griffin et al. (1998) and Sheng et al. (1996, 1998) argue that plaque-associated IL-1 elevations in Down's syndrome and AD brains play an important role in cytokine circuits promoting GFAP and $\mathrm{S} 100 \beta$ overexpression, APP synthesis, astrocyte activation, dystrophic neurite formation, and neuritic plaque pathogenesis. In particular, dystrophic neurites, the hallmark of neuritic plaques, appear closely correlated with activated microglia and are hypothesized to be induced by cytokines from activated microglia. Increased expression of IL- $1 \beta$ has also been implicated in memory 
Table 1. Image analysis of DAE-positive (A $\beta$-positive) structures

\begin{tabular}{lcccc} 
& $\operatorname{Tg}(+)$ control & $\operatorname{Tg}(+)$ ibuprofen & Percent change & $p$ value \\
\hline Number of plaques & $74.8 \pm 13.1$ & $35.4 \pm 10.5$ & $\downarrow 52.6 \%$ & 0.02 \\
Mean area of plaques $\left(\mu \mathrm{m}^{2}\right)$ & $710.8 \pm 96.8$ & $671.1 \pm 122.1$ & No change & 0.85 \\
Mean \% area of plaques & $0.331 \pm 0.065$ & $0.156 \pm 0.05$ & $\downarrow 52.9 \%$ & 0.07 \\
Total area of plaques $\left(\mu \mathrm{m}^{2}\right)$ & $48,485.2 \pm 8,523.7$ & $21,398.6 \pm 6,314.8$ & $\downarrow 55.9 \%$ & 0.02
\end{tabular}

DAE is antibody against $A \beta$ 1-13. Using NIH Image public domain software, data analyzed by two-way ANOVA (diet $\times$ region). Analyses were performed on 1570 plaques from $\mathrm{Tg}+$ mice fed control diet $(n=7$; three sections per animal) and 461 plaques in $\mathrm{Tg}+$ mice fed ibuprofen diet $(n=5$; three sections per animal). Values are mean \pm SE. Logarithmic transformation was needed for homogeneity of variance (Bartlett's test) with total area of plaques. Treatment effects were not dependent on region $(p=0.68-98)$.

A

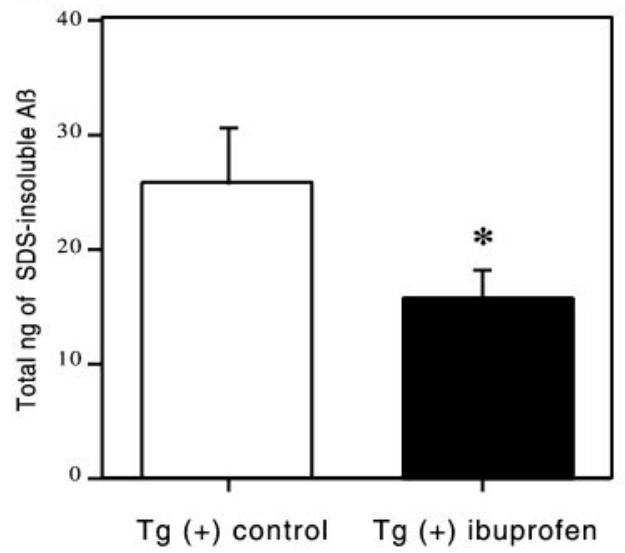

B

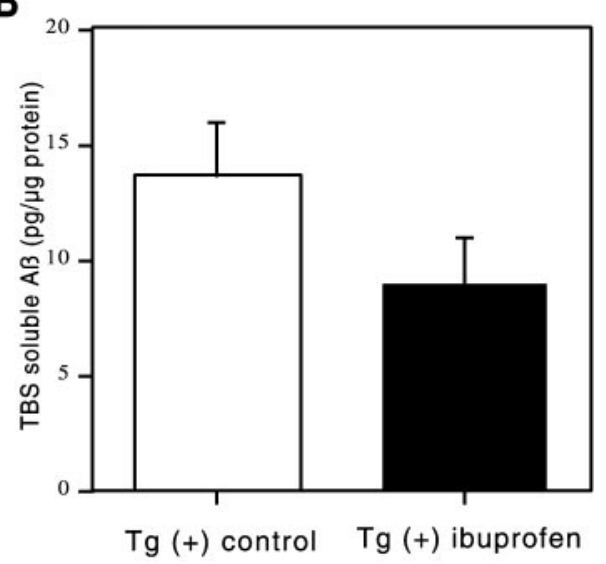

Figure 4. ELISA measurement of watersoluble and SDS-insoluble A $\beta$. These histograms illustrate $A \beta$ levels plus or minus $95 \%$ confidence interval of formic acidextracted (SDS-insoluble) A $\beta$ (nanograms per total pellet) or soluble $A \beta$ (picograms per microgram of protein) as measured by sandwich ELISA for dissected brain regions of the Tg2576 brain. A two-way ANOVA (treatment $\times$ region) showed significant treatment effects in insoluble $\mathrm{A} \beta$ levels $\left({ }^{*} p<0.05\right)$ and regional effects $(p<0.0001)$ with no treatmentregion interaction. Decreases in soluble $\mathrm{A} \beta$ levels were consistent in all regions but did not quite reach statistical significance $(p=0.06)$.

Table 2. Image analysis of ubiquitin-positive particles

\begin{tabular}{lcccl} 
& $\operatorname{Tg}(+)$ control & $\operatorname{Tg}(+)$ ibuprofen & Percent change & $p$ value \\
\hline Numbers of small particles & $77.05 \pm 13.8$ & $40.5 \pm 10.1$ & $\downarrow 47.5 \%$ & 0.03 \\
Area of small particles $\left(\mu \mathrm{m}^{2}\right)$ & $100.1 \pm 6.8$ & $131.1 \pm 14.1$ & $\uparrow 31 \%$ & 0.03 \\
$\%$ area of small particle & $0.049 \pm 0.01$ & $0.016 \pm 0.005$ & $\downarrow 67.3 \%$ & 0.005 \\
Total area of small particles $\left(\mu \mathrm{m}^{2}\right)$ & $7865.1 \pm 1321.1$ & $3871.4 \pm 876.1$ & $\downarrow 50.8 \%$ & 0.01
\end{tabular}

Using NIH Image public domain software, data were analyzed by two-way ANOVA (diet $\times$ region). Analyses were performed on 1618 small particles in $\mathrm{Tg}+$ mice fed control diet $(n=7$; three sections per animal) and 505 small particles in $\mathrm{Tg}+$ mice fed ibuprofen diet $(n=5$; three sections per animal). Values are mean \pm SE. Treatment effects were not dependent on region. Square root or logarithmic transformations were required for equality of variance for total area, size, and percentage area of small particles.

deficits and reduced long-term potentiation in aging rat hippocampus (Lynch, 1998). Our results show that chronic administration of ibuprofen prevents transgene- and age-related increases in brain levels of the inflammatory cytokine IL-1 $\beta$ in $\mathrm{Tg} 2576$ mice. This treatment also diminished the proliferation of activated microglia associated with amyloid plaques and decreased the number of ubiquitin-positive dystrophic neurites in plaque-forming regions of these mice. A significant reduction in overall dystrophic neurite formation may have resulted from a decrease in amyloid plaque number and a weakened microglial response surrounding plaques. Neuritic plaques are an important endpoint because increased density of neocortical neuritic plaques is associated with even very mild dementia (Haroutunian et al., 1998) and correlates with cognitive deficits (Nagy et al., 1995).

Interestingly, ring analyses of the microglial response to ibuprofen within and around plaques showed a more marked attenuation in ring 2 just outside plaques than in ring 1 located within plaques of 40 and $25 \%$, respectively. This positional effect is consistent with a report showing NSAIDs markedly reducing microglia numbers outside and surrounding plaques in elderly, nondemented controls and arthritic patients, but producing a smaller effect on microglia in "close physical association with the plaque" (Mackenzie and Munoz, 1998).
The ibuprofen dose our mice received was estimated to be $\sim 56$ $\mathrm{mg} / \mathrm{kg}$ of ibuprofen per day, a dose considered high enough to both inhibit cyclooxygenase $(\mathrm{COX})$ and stimulate peroxisome proliferator-activated receptors- $\gamma$ (PPAR- $\gamma \mathrm{s})$, the two main pharmacological targets of ibuprofen and other NSAIDs (Lehmann et al., 1997; Combs et al., 2000). Because both COX and PPAR $\gamma$ expression are increased in Alzheimer brains (Kitamura et al., 1999), it is likely that at least some effects of ibuprofen on AD pathology are mediated through changes in the activities of these enzymes. COX inhibitors decrease production of prostaglandins, a major extracellular signal that can induce neuronal degeneration (Prasad et al., 1998). PPAR- $\gamma$ agonists inhibit inflammatory cytokine synthesis by monocytic lineage cells, including IL-1, and block A $\beta$-stimulated expression of IL- 1 and TNF- $\alpha$ by microglia, and thus may be important in controlling $\mathrm{A} \beta$-mediated microglial inflammatory responses (Combs et al., 2000). Whether lower, safer doses of ibuprofen, such as $5-20 \mathrm{mg} / \mathrm{kg}(400-1000 \mathrm{mg} / \mathrm{d}$ in humans), are effective in delaying $\mathrm{AD}$ pathogenesis remains to be tested. If COX inhibition is the critical step, doses in this range, which are known to diminish centrally mediated nociceptive activity (Ferrari et al., 1990; Lotsch et al., 1997) and decrease prostaglandin levels in the mouse brain (Fitzpatrick and Wynalda, 1976), but are less effective in ameliorating peripheral inflammation in 
arthritis (Garcia Rodriguez, 1997), may nevertheless be beneficial in AD.

Our results show that a widely used NSAID, ibuprofen, can significantly delay both CNS inflammation and Alzheimer plaque deposition in the Tg2576 mouse model for AD. An effect at an early stage of plaque formation is proposed and is consistent with the reduced AD risk associated with chronic NSAID consumption in epidemiological studies. Studies in this and other mouse models will better define the choice of NSAIDs, appropriate target stages of disease, and doses for AD prevention or treatment in humans.

\section{REFERENCES}

Ard MD, Cole GM, Wei J, Mehrle AP, Fratkin JD (1996) Scavenging of Alzheimer's amyloid beta-protein by microglia in culture. J Neurosci Res 43:190-202.

Benzing WC, Wujek JR, Ward EK, Shaffer D, Ashe KH, Younkin SG, Brunden KR (2000) Evidence for glial-mediated inflammation in aged APPSw transgenic mice. Neurobiol Aging 20:581-589.

Breitner JCS, Welsh KA, Helms MJ, Gaskell PC, Gau BA, Roses AD, Pericak-Vance MA, Saunders AM (1995) Delayed onset of Alzheimer's disease with nonsteroidal anti-inflammatory and histamine $\mathrm{H} 2$ blocking drugs. Neurobiol Aging 16:523-530.

Combs CK, Johnson DE, Karlo JC, Cannady SB, Landreth GE (2000) Inflammatory mechanisms in Alzheimer's disease: inhibition of $\beta$-amyloid-stimulated proinflammatory responses and neurotoxicity by PPAR $\gamma$ agonists. J Neurosci 20:558-567.

Dickson DW, Lee SC, Mattiace LA, Yen S-HC, Brosnan C (1993) Microglia and cytokines in neurological disease, with special reference to AIDS and Alzheimer's disease. Glia 7:75-83.

Ferrari RA, Ward SJ, Zobre CM, Van Liew DK, Perrone MH, Connell MJ, Haubrich DR (1990) Estimation of the in vivo effect of cyclooxygenase inhibitors on prostaglandin $\mathrm{E}_{2}$ levels in mouse brain. Eur J Pharmacol 179:25-34.

Fitzpatrick FA, Wynalda MA (1976) In vivo suppression of prostaglandin biosynthesis by non-steroidal anti-inflammatory agents. Prostaglandins 12:1037-1051.

Franklin KBJ, Paxinos G (1997) The mouse brain in stereotaxic coordinates, Ed 1. London: Academic.

Frautschy SA, Yang F, Irrizarry M, Hyman B, Saido TC, Hsiao K, Cole GM (1998) Microglial response to amyloid plaques in APPsw transgenic mice. Am J Pathol 152:307-317.

Garcia Rodriguez LA (1997) Nonsteroidal anti-inflammatory drugs, ulcers and risk: a collaborative meta-analysis. Semin Arthritis Rheum $26: 16-20$.

Griffin WS, Sheng JG, Royston MC, Gentleman SM, McKenzie JE, Graham DI, Roberts GW, Mrak RE (1998) Glial-neuronal interactions in Alzheimer's disease: the potential role of a "cytokine cycle" in disease progression. Brain Pathol 8:65-72.

Haroutunian V, Perl DP, Purohit DP, Marin D, Khan K, Lantz M, Davis KL, Mohs RC (1998) Regional distribution of neuritic plaques in the nondemented elderly and subjects with very mild Alzheimer disease. Arch Neurol 55:1185-1191.

Harris-White ME, Chu T, Balverde Z, Sigel JJ, Flanders KC, Frautschy SA (1998) Effects of transforming growth factor-beta (Isoforms 1-3) on amyloid-beta deposition, inflammation, and cell targeting in organotypic hippocampal slice cultures. J Neurosci 18:10366-10374.

Hsiao K, Chapman P, Nilsen S, Eckman C, Harigaya Y, Younkin S, Yang F, Cole G (1996) Correlative memory deficits, Abeta elevation, and amyloid plaques in transgenic mice. Science 274:99-102.
In 't Veld BA, Launer LJ, Hoes AW, Ott A, Hofman A, Breteler MMB, Stricker BHC (1998) NSAIDs and incident Alzheimer's disease. The Rotterdam study. Neurobiol Aging 19:607-611.

Irizarry MC, McNamara M, Fedorchak K, Hsiao K, Hyman BT (1997) APPsw transgenic mice develop age-related $\mathrm{A} \beta$ deposits and neuropil abnormalities, but no neuronal loss in CA1. J Neuropathol Exp Neurol 56:965-973.

Kitamura Y, Shimohama S, Koike H, Kakimura J-I, Matsuoka Y, Nomura Y, Gebicke-Haerter PJ, Tanigushi T (1999) Increased expression of cyclooxygenases and peroxisome proliferator-activated receptor- $\gamma$ in Alzheimer's disease brain. Biochem Biophys Res Commun 254:582-586. Kuo YM, Emmerling MR, Vigo-Pelfrey C, Kasunic TC, Kirkpatrick JB, Murdoch GH, Ball MJ, Roher AE (1996) Water-soluble Abeta (n-40, $\mathrm{N}-42$ ) oligomers in normal and Alzheimer disease brains. J Biol Chem 271:4077-4081.

Laping NJ, Teter B, Nichols NR, Rozovsky I, Finch CE (1994) Glial fibrillary acidic protein: regulation by hormones, cytokines, and growth factors. Brain Pathol 1:259-275.

Lehmann JM, Lenhard JM, Oliver BB, Ringold GM, Kliewer SA (1997) Peroxisome proliferator-activated receptors $\alpha$ and $\gamma$ are activated by indomethacin and other non-steroidal anti-inflammatory drugs. J Biol Chem 272:3406-3410.

Lotsch J, Hummel T, Kraetsch H, Kobal G (1997) The negative mucosal potential: separating central and peripheral effects of NSAIDs in man. Eur J Clin Pharmacol 52:359-364.

Lynch MA (1998) Age-related impairment in long-term potentiation in hippocampus: a role for the cytokine, interleukin-1 beta? Prog Neurobiol 56:571-589.

Mackenzie IR, Hao C, Munoz DG (1995) Role of microglia in senile plaque formation. Neurobiol Aging 16:797-804.

Mackenzie IR, Munoz DG (1998) Nonsteroidal anti-inflammatory drug use and Alzheimer-type pathology in aging. Neurology 50:986-990.

Mak K, Yang F, Vinters HV, Frautschy SA, Cole GM (1994) Polyclonals to $\beta$-amyloid (1-42) identify most plaque and vascular deposits in Alzheimer cortex, but not striatum. Brain Res 667:138-142.

McGeer EG, McGeer PL (1998) The importance of inflammatory mechanisms in Alzheimer disease. Exp Gerontol 33:371-378.

Mrak RE, Sheng JG, Griffin WS (1995) Glial cytokines in Alzheimer's disease: review and pathogenic implications. Hum Pathol 26:816-823.

Nagy Z, Esiri MM, Jobst KA, Morris JH, King EM, McDonald B, Litchfield S, Smith A, Barnetson L, Smith AD (1995) Relative roles of plaques and tangles in the dementia of Alzheimer's disease: correlations using three sets of neuropathological criteria. Dementia 6:21-31.

Prasad KN, Hovland AR, La Rosa FG, Hovland PG (1998) Prostaglandins as putative neurotoxins in Alzheimer's disease. Proc Soc Exp Biol 219:120-125.

Rogers J, Webster S, Lue L-F, Brachova L, Civin WH, Emmerling M, Shivers B, Walker D, McGeer P (1996) Inflammation and Alzheimer's disease pathogenesis. Neurobiol Aging 17:681-686.

Sheng JG, Ito K, Skinner RD, Mrak RE, Rovnaghi CR, Van Eldik LJ, Griffin WS (1996) In vivo and in vitro evidence supporting a role for the inflammatory cytokine interleukin-1 as a driving force in Alzheimer pathogenesis. Neurobiol Aging 17:761-766.

Sheng JG, Griffin WS, Royston MC, Mrak RE (1998) Distribution of interleukin-1-immunoreactive microglia in cerebral cortical layers: implications for neuritic plaque formation in Alzheimer's disease. Neuropathol Appl Neurobiol 24:278-283.

Stewart WF, Kawas C, Corrada M, Metter EJ (1997) Risk of Alzheimer's disease and duration of NSAID use. Neurology 48:626-632.

Wyss-Coray T, Masliah E, Mallory M, McConlogue L, Johnson-Wood K, Lin C, Mucke L (1997) Amyloidogenic role of cytokine TGF-beta-1 in transgenic mice and in Alzheimer's disease. Nature 389:603-605. 